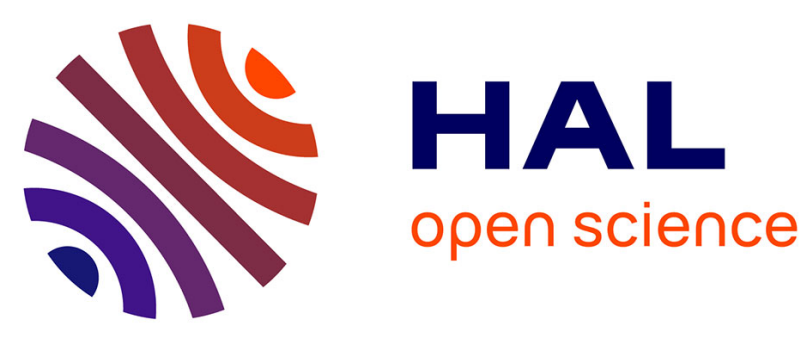

\title{
THE METALLURGICAL ASPECTS OF ALUMINIUM-LITHIUM ALLOYS IN VARIOUS PRODUCT FORMS FOR HELICOPTER STRUCTURAL APPLICATIONS
}

A. Smith

\section{To cite this version:}

A. Smith. THE METALLURGICAL ASPECTS OF ALUMINIUM-LITHIUM ALLOYS IN VARIOUS PRODUCT FORMS FOR HELICOPTER STRUCTURAL APPLICATIONS. Journal de Physique Colloques, 1987, 48 (C3), pp.C3-49-C3-59. 10.1051/jphyscol:1987307 . jpa-00226530

HAL Id: jpa-00226530 https://hal.science/jpa-00226530

Submitted on 1 Jan 1987

HAL is a multi-disciplinary open access archive for the deposit and dissemination of scientific research documents, whether they are published or not. The documents may come from teaching and research institutions in France or abroad, or from public or private research centers.
L'archive ouverte pluridisciplinaire HAL, est destinée au dépôt et à la diffusion de documents scientifiques de niveau recherche, publiés ou non, émanant des établissements d'enseignement et de recherche français ou étrangers, des laboratoires publics ou privés. 
THE METALLURGICAL ASPECTS OF ALUMINIUM-LITHIUM ALLOYS IN VARIOUS PRODUCT FORMS FOR HELICOPTER STRUCTURAL APPLICATIONS

\author{
A.F. SMITH \\ Materials Laboratory, Westland Helicopters Ltd, \\ GB-Yeovil, BA2O 2YB, Somerset, Great-Britain
}

\begin{abstract}
The reduced density and concommitant increased elastic modulus of aluminium-lithium based alloys have created intense interest throughout the aerospace industry and associated organisations since the beginning of the present decade. Many Companies and Establishments have evaluated the new alloys to have emerged with a view to potential incorporation into their specific products and this paper describes the results from a number of such metallurgical examinations undertaken at WESTLAND HELICOPTERS during the past four years.
\end{abstract}

This paper reports on some of the studies of wrought product forms in alloys 8090,8091 and $9052 \mathrm{XL}$. Microstructural investigations and mechanical property data such as tensile, compression, fatigue and fracture toughness are presented and have generally shown these new materials to exhibit properties which match those of currently used non-lithium containing aluminium alloys; the results of some of these parallel and comparative studies are included in the paper.

Finally, mention is made of aspects of which aluminium-lithium alloys show some deficiencies and any problems anticipated in their future use will be briefly discussed.

\title{
INTRODUCTION
}

Previous attempts to commercially exploit aluminium-lithium based alloys have been largely unsuccessful, due mainly to notch sensitivity and fracture toughness deficiencies such as those encountered in the now - obsolete 2020 'ingot metallurgy' alloy of the $1960^{\prime} \mathrm{s}$ (1). However, due primarily to the increasing demands of the aerospace industry, recent years have witnessed a renewed interest in these metals and has culminated in the emergence of a new family of aluminium-based alloys which, compared to current aluminium alloys, exhibit density reductions of $8-12 \%$ with a concommitant $\sim 10 \%$ increase in elastic modulus, but generally without degradation of other properties.

From the outset, the aluminium companies adopted a policy whereby most airframe manufacturers were provided with alloy samples as development progressed, thus enabling considerable experience to be gained at a relatively early stage. Batches of the new alloys were first supplied to WESTLAND HELICOPTERS by Alcan International Ltd/British Alcan Aluminium in 1983 and consisted of development grade sheet, plate and extruded bar primarily in the 8090 'ingot metallurgy' alloy for evaluation purposes. Since that time, the above and other companies have supplied further alloys and product forms, including a small quantity of the 'powder metallurgy' mechanically alloyed $9052 \mathrm{XL}$ composition from the Inco subsidiary, Novamet Aluminium. 
Notwithstanding some property deficiencies which are to be expected from material of an experimental nature, the otherwise promising behaviour revealed by these early studies, have created sufficient confidence to now warrant initiation of extensive work programmes to evaluate and qualify the more advanced of the new compositions, now of full production status, for potential incorporation in the EH101 helicopter, fig 1 , $a$ collaborative venture between WESTLAND HELICOPTERS of England and Giovanni Agusta of Italy. Whilst the development of this aircraft is at too advanced a stage to permit exploitation of both the reduced density and the increased modulus of aluminium-lithiumalloys, essential weight savings solely from the former property are, nevertheless, anticipated through direct substitution for current, non-lithium containing aluminium alloys.

The findings reported in this paper derive predominantly from studies of development grade material, having been selected to indicate both the positive and negative aspects of the new alloys which may directly affect their potential usage in helicopter and fixed wing airframes. It should be remembered, however, that the new generation of aluminium-lithium based alloys has progressed from small scale laboratory activities to, in one case at least, full production status in a mere six years or so and, accordingly, further developments may be anticipated in the near future.

\section{Alloy composition and density}

Whilst binary aluminium-lithium alloys would produce maximum density reductions, precipitation solely of the $\delta^{\prime}-\mathrm{Al}_{3} \mathrm{Li}$ phase would result in poor ductility and fracture toughness. $(2,3)$. Accordingly, improvements in these properties are achieved in commercial 'ingot metallurgy' materials primarily by co-precipitation of further intermediate phase particles such as $\mathrm{S}^{\prime}-\mathrm{Al}_{2} \mathrm{CuMg}_{\text {(4) }}$ or $\theta^{\prime} / \theta^{\prime \prime}-\mathrm{CuAl}_{2}$ (5) which are attributable to the additional inclusion of copper and magnesium as alloying elements. To achieve maximum strengthening, fine particles of the latter phases need to be homogeneously dispersed throughout the aluminium matrix and while certain Cu:Mg ratios such as those in the Pechiney CP276 alloy will allow this during simple solution and ageing heat treatments, other alloys with unfavourable $\mathrm{Cu}: \mathrm{Mg}$ ratios such as 8090 , require the introduction of suitable nucleation centres. This leads to a characteristic feature of a number of the 'ingot metallurgy' aluminium-lithium based alloys where the application of a 1-6\% cold stretch between solution and ageing treatments (or cold compression in forgings) has the effect of introducing numerous nucleation sites via a dislocation network and, in certain alloys, is necessary to achieve optimum properties. In such compositions, the absence of these stimuli results in precipitation of copper/magnesium/lithium containing phases predominantly as relatively coarse particles which contribute iitle hardening, accounting for the lower properties of, for example, 8090 in stretch-free tempers where strengthening is almost solely due to $\delta^{\prime}-\mathrm{Al}_{3} \mathrm{Li}$ precipitation. Further, in all current commercial ingot-metallurgy alloys, additional strengthening is provided by the presence of zirconium which, whilst being a highly efficient grain refiner, also acts as a recrystallisation inhibitor. 
Structural characteristics differing significantly from the above are exhibited in materials produced by mechanically alloying, a high energy dry milling technique whereby the repetitive plastic deformation, cold welding and fracture of the powdered constituents results in highly homogenous powders of the desired composition (6-9). Excessive welding of the powders is prevented by the addition of organic lubricants which, during subsequent consolidation by vacuum hot pressing and extrusion, decompose to form a fine dispersion of $\mathrm{Al}_{4} \mathrm{C}_{3}$ particles. Together with $\mathrm{Al}_{2}^{4} \mathrm{O}_{3}^{3}$ particles derived from the original aluminium powder, these confer dispersion strengthening upon the matrix and with the stable, ultra fine grain size, constitute the main attractions of this material. Since heat treatments of the customary solution treatment + precipitation hardening types are not needed, the problems of quenching stresses in thicker section components are eliminated. Lithium, therefore makes no contribution to properties in these 'powder metallurgy' alloys and is added merely to reduce density.

clearly, wrought alloy density is determined dicectly by chemical composition and the following relationship due to Peel (10) has proved useful as a check on chemical analysis of metal received at WESTLAND HELICOPTERS for evaluation.

$$
\begin{aligned}
\text { Density }= & 2.71+0.024 \mathrm{Cu}_{3}+0.018 \mathrm{Zn}+0.022 \mathrm{Mn}-0.079 \mathrm{Li}-0.01 \mathrm{Mg} \\
& -0.004 \mathrm{Si} \mathrm{gcm}^{-3} .
\end{aligned}
$$

where the atomic symbols represent the composition of that element in weight per cent. Theoretical density comparisons $3^{\text {ith }}$ experimental values is generally excellent with agreement to $\pm 0.01 \mathrm{gcm}^{-3}$ usually achieved.

Perhaps the most advanced of the new alloys to date is the 8090 composition and fig. 2 confirms the approximate $10 \%$ density reduction compared with its currently used, non-lithium containing 2014 counterpart.

\section{Surface Elemental Depletion}

When exposed to relatively high temperatures in the presence of air, aluminiumlithium based alloys exhibit two unusual but, apparently related features. First1y, due primarily to their strong oxidising tendencies, depletion of lithium (and magnesium) readily occurs from the metal surface which, in the precipitation hardening 'ingot metallurgy' alloys, in manifest as microharness gradients. Being essentially diffusion controlled, the extent of depletion is a function of both time and temperature as illustrated for 8090 sheet by the family of curves in fig. 3, where the data for $510^{\circ}$ and $530^{\circ}$ simulate up to three consecutive solution heat treatments (prior to ageing), each of twenty minutes duration. 


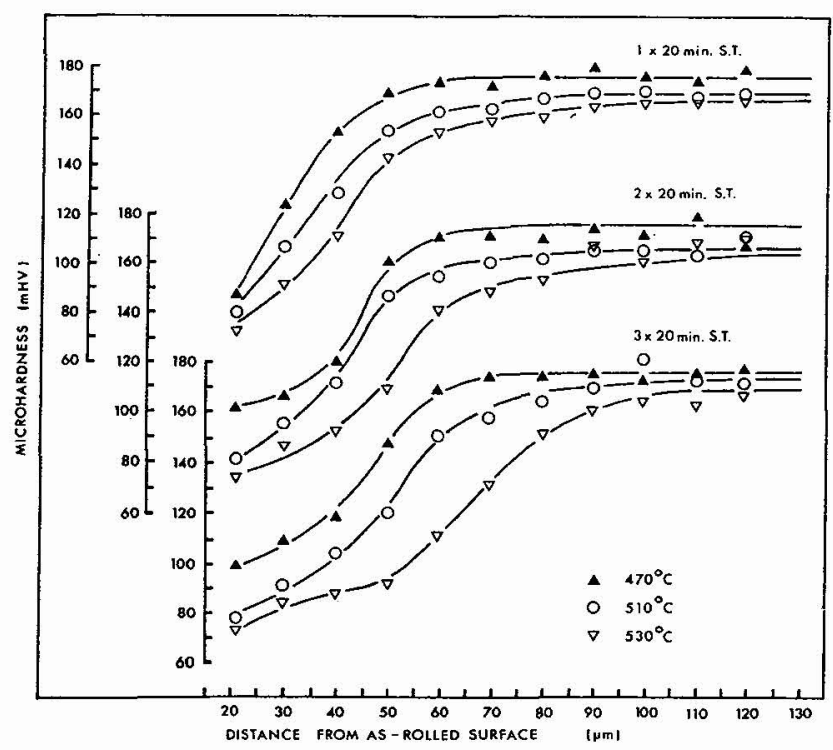

Fig. 3. Metal surface microhardness profiles due to lithium and magnesium depletion in 8090-T6 sheet.

Secondly,

polished microsections exhibit a feature which is indicative of a band of sub-surface porosity, fig. 4, while fig. 5 illustrates the experimentally observed relationship between these phenomena. The origin of the 'pores' is currently unclear. Whilst one hypothesis (11) attributes them to agglomeration of vacancies which arise from the lithium and magnesium diffusion to, and subsequent depletion from the metal surface, this does not adequately explain the 'pore'-free band immediately adjacent to the surface. An alternative explanation suggests that the 'pores' are

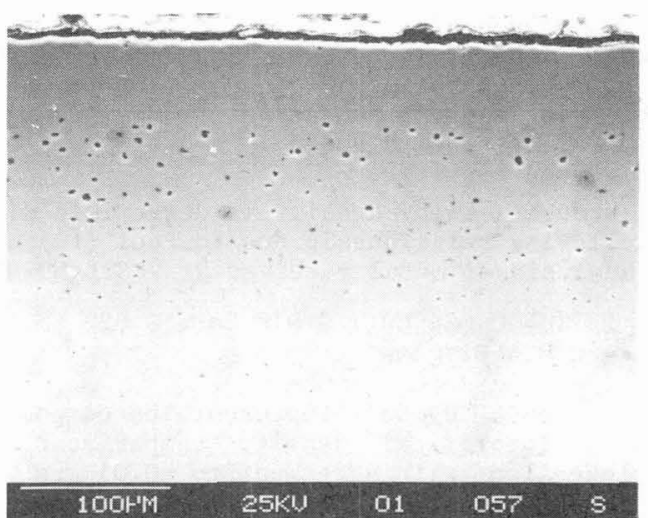

Fig. 4. Apparent sub-surface 'porosity' in 8090 polished microsections only such on polished microsections and arise from the fragmentation and loss during metallographic 


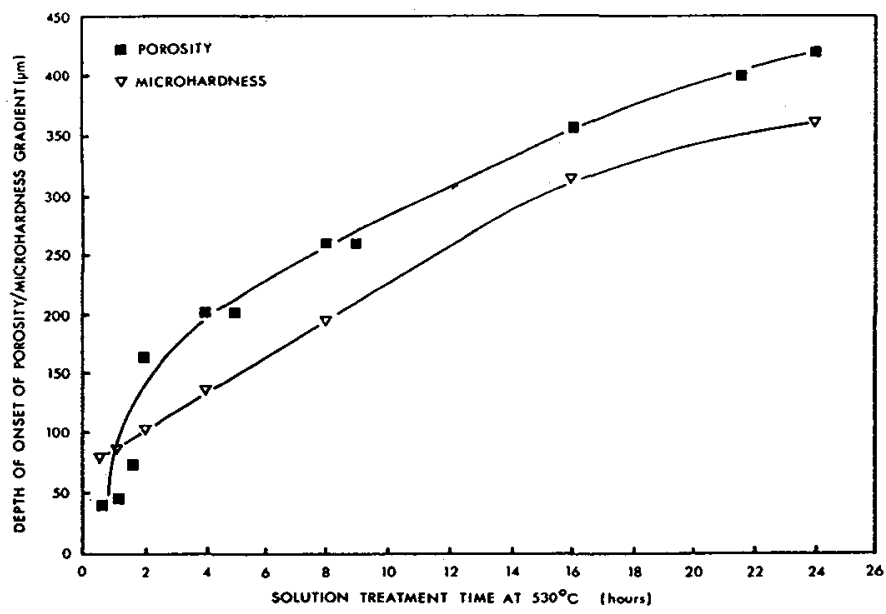

Fig. 5. Depth of onset of sub-surface 'porosity' and micro-hardness gradient as a function of solution treatment time.

preparation of the brittle, equilibrium $\delta$-AlLi phase (12). Whilst this compound should not be present after the metal processing and heat treatments, localised elemental modifications associated with lithium and magnesium depletion may have created the necessary conditions for its formation.

As far as the metal user is concerned, the ramifications of these features are primarily dependent upon product form and size. In the case of thin sheet, the short solution treatment times employed would be expected to produce relatively shallow depleted surface layers which would be partially removed during the pickling and anodising pretreatments prior to the painting of helicopter structural components. Notwithstanding the greater depleted depths arising from the longer solution treatment times used for plate and extruded bar, these features, nevertheless, are likely to be removed by machining and finishing of these product forms. However, they may be more problematic in thin sections of components such as variable section extruded profiles, precise-to-form forgings where extended solution treatment times may be necessitated. In these circumstances, the use of salt baths or inert gas atmospheres may be beneficial, as the exclusion of oxygen minimises surface elemental depletion.

\section{Mechanical Properties of Sheet}

Excepting density and elastic modulus, the properties of the new metals are generally -aimed at those of the current $2 \times x x$ and $7 \times x x$ aluminium alioys. Although not strictly correct, potential usage of the new alloys on a substitutional basis often necessary entails comparisons between alloys in different clad/unclad conditions and pertains to the situation at WESTLAND HELICOPTERS where unclad 8090 sheet is viewed as a lightweight replacement for clad 2014A-T6 (BS L165-0.2\% PS, and TS of $345 \mathrm{MPa}$ and $415 \mathrm{MPa}$ respectively), notwithstanding the fact that the minimum properties of the new alloy were originally targetted at those of unclad 2014A-T6 (L159-0.2\% PS and TS of 370 $\mathrm{MPa}$ and $430 \mathrm{MPa}$ respectively). Fig. 6 illustrates the noticeable measured property differences of unclad 8090-T62 and clad 2014A-T62 sheet, although it is noted that the majority of 8090 strengths nevertheless achieve the minimum L165 specification requirements which, together with the property improvements recently demonstrated in production grade 8090 , place this particular aluminium-lithium alloy as a prime candidate for potential substitution into helicopter structures. 

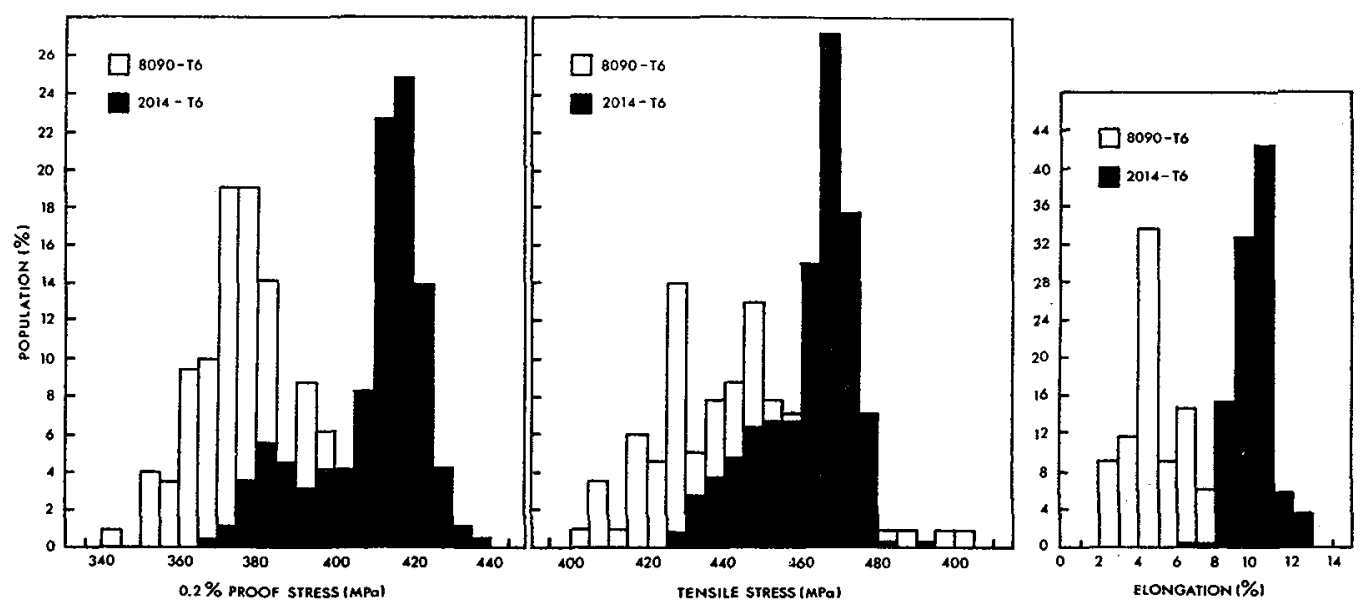

Fig. 6. Transverse tensile properties of unclad 8090-T62 and clad 2014A-T62 sheet.

A characteristic of 'ingot metallurgy' aluminium-lithium based alloys in the unrecrystallised state and in all wrought product forms is the presence of pronounced crystallographic textures which are manifest as anisotropic mechanical behaviour, fig. 7, the distinct drop in properties at an angle of $50-60^{\circ}$ to the direction of working being of concern as these may be below the specification minima, notwi thstanding attractive longitudinal and long transverse levels. However, it is of interest to note that similar features, albeit of a lesser degree, have been measured in 2014 sheet.

An attractive feature of aluminium-lithium alloys is their relatively low sensitivity to quenching rates, still air cooling of 8090 sheet having been shown to result in only a 3-6\% decrease in subsequent precipitated mechanical strength compared to that obtained after cold water quenching and ageing. This is of importance combined with the superplastic forming capability of these materials, enabling adequate properties to be achieved by directly ageing the as-formed component, without the need for re-solution treatment which would largely destroy the superplastically formed shape.

Further, greater weight savings can be achieved through substitution of superplastically formed aluminium-lithium components for the currently used 'SUPRAL' alloys as higher copper contents of the latter produce higher densities of $\sim 2.85 \mathrm{gcm}^{-3}$ compared to typical values of $\sim 2.80 \mathrm{gcm}^{-3}$ for $2014 \mathrm{~A}$ alloy.

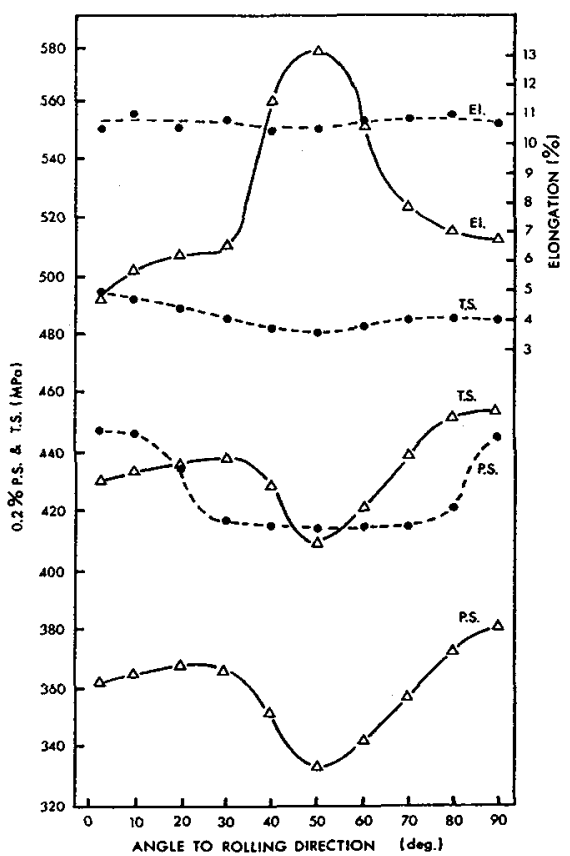

Fig. 7. Anisotropy of mechanical properties of 8090-T62 $(\Delta)$ and 2014A - T851 (•) sheet.

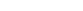


Mechanical properties of extruded bar

A study of mechanical properties in 8090-T6511 extruded bar have exhibited a noticeable location dependence, again attributable primarily to texture effects. Fig. 8 shows significant differences across the bar (L-T direction) whilst fig. 9 indicates variations throughout the thickness ( $\mathrm{S}-\mathrm{T}$ direction). It is noted that longitudinal strength properties at all locations greatly exceed the minimum values required by the specifications for 2014A-T6511 (BS L168-0.2\% PS, TS and elongations of $415 \mathrm{MPa}, 460 \mathrm{MPa}$ and $7 \%$ respectively) and 7075-T73511 (BS L160-0.2\% PS, TS and elongation of $420 \mathrm{MPa} ; \quad 485 \mathrm{MPa}$ and $8 \%$ respectively). Characteristically lower ductilities are also achieved. As with the 8090 sheet, extruded bar exhibits noticeable anisotropy, with minimum $0.2 \%$ PS and TS levels of 340 $\mathrm{MPa}$ and $460 \mathrm{MPa}$ at an angle of $60^{\circ}$ to the extrusion direction.

Examination

of

'powder-metallurgy' alloyed 9052XL material has also been carried out upon extruded bar form. Metallurgical characterisation showed a very fine, uniform grain size typically of $\sim 1 \mu \mathrm{m}$ and $\mathrm{x}$-ray diffraction studies indicated the presence of $\mathrm{Al}_{4} \mathrm{C}_{3}$ together with unidentifiable particles assumed to be complex dispersoids of aluminium, lithium, magnesium, oxygen and carbon. Heat treatment studies showed precipitation hardening effects to be absent and as-extruded properties were relatively unaffected by heating at $500^{\circ} \mathrm{C}$ for $0.5 \mathrm{~h}$ to simulate thermal effects during a forging operation, consistent with the dispersion-strengthened nature of this material. Typical mechanical properties are illustrated in fig. 10 which shows them to be comparable with the aforementioned 8090 extruded bar but with noticeable improvements in long transverse $0.2 \%$ PS values.

\section{Mechanical properties of plate}

8090-T651 alloy plate properties have been found to be location dependent throughout the thickness with maximum values occuring at the $1 / 2 t$ position, the converse of the 8090 extruded bar. Fig. 11 shows that although 8090 strength properties generally

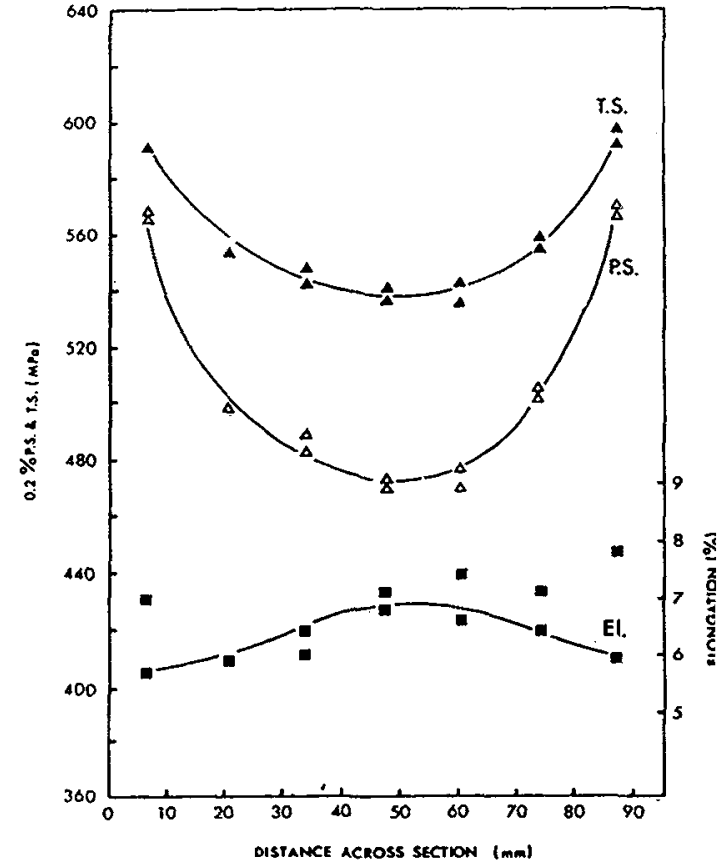

Fig. 8. Longitudinal 8090-T6511 extruded bar properties as a function of position across the section.

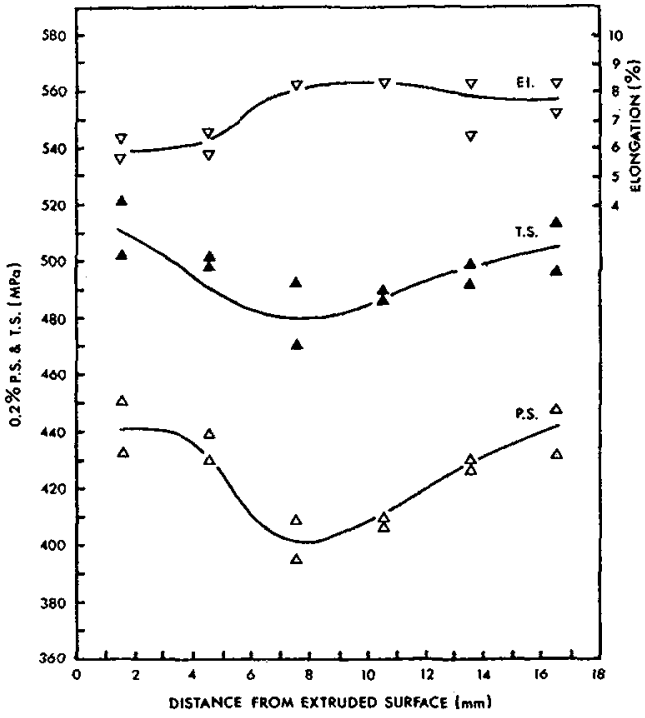

Fig. 9. Through-section, long transverse mechanical properties of $19 \mathrm{~mm}$ thick 8090 T6511 extruded bar. 


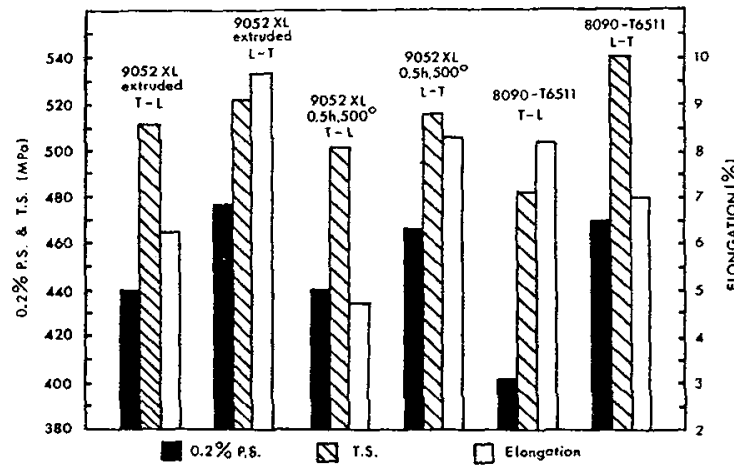

Fig. 10. Mechanical properties of $9052 \times L$ extruded bar compared to those of 8090-T6511.

exceed the corresponding 2014A-T651 (BS L93) minimum levels, typical values were not always achieved. However, it is emphasised that the aluminium-lithium used in these studies was of early quality and tests on recent production standard metal have shown significant improvements, with typical properties comparable to L93 now readily achieved.

Fig. 12 shows corresponding fracture toughness data, Kic values having been calculated from the measured ratio of notched tensile strength/0.2\% proof stress. Again, considering the early nature of the alloy tested, properties are very promising and further improvements have been reported for production grade 8090, especially when employing ageing schedules specifically developed to enhanced this property.

A comparison of tension and compression $0.2 \%$ PS properties of 8090 and 8091 plate is shown in fig. 13. Higher tension values are noted in the longitudinal direction but with corresponding lower compression levels due to relatively easy failure along grain boundaries elongated in the rolling direction; the converse situation occurs in the long. transverse direction where compression properties are higher.

As far as helicopter structures are concerned, the new alloys in this product form are perhaps of least interest as the utilisation rate of plate for major components such as lift frames is often as low as $\sim 5 \%$ and becomes economically unatractive when considering the present three to five fold increased raw material cost of aluminium-lithium. Due to these factors, greater utilisation of die forgings (in aluminium lithium alloys) is being considered in order to achieve significant reductions in machined scrap rates.
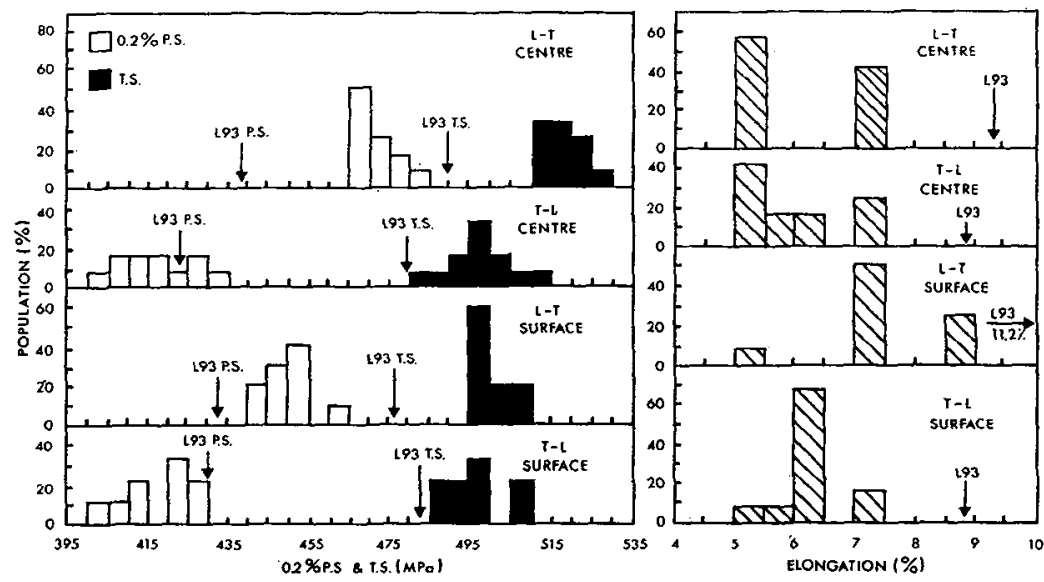

Fig. 11. Histograms of $8090-T 651$ plate properties with measured $\mathrm{L} 93$ mean values. 


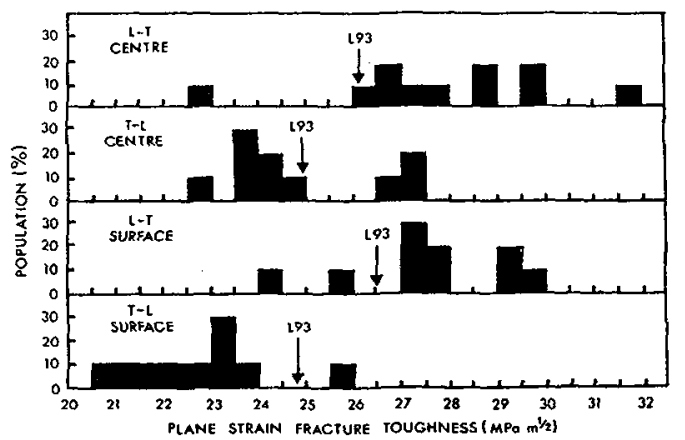

Fig. 12. Histograms of plane strain fracture toughness of 8090-T651 plate with 2014-T651 (L93) mean values, both derived from $\sigma_{\text {nts }} / \sigma_{\mathrm{ps}}$ ratios.

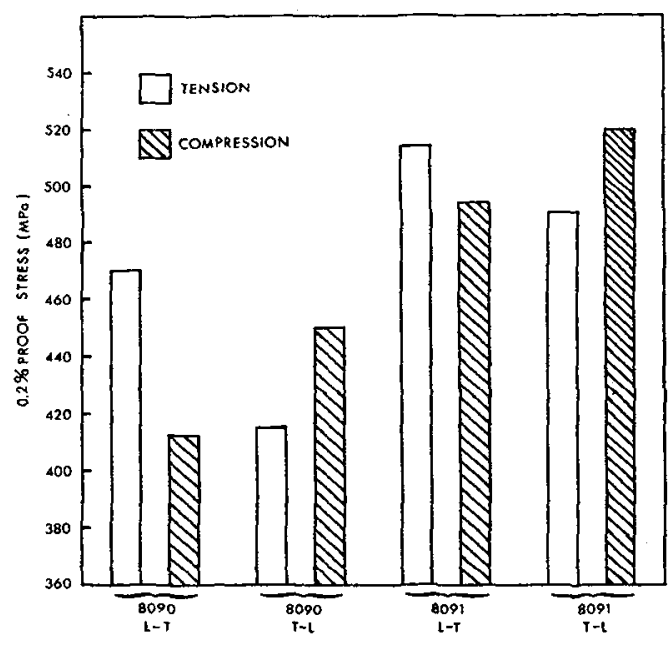

Fig. 13. Tension and compression $0.2 \%$ PS. of 8090 and $8091-T 65125 \mathrm{~mm}$ plate.
Fatigue

Fatigue testing of various aluminium-lithium alloys have generally substantiated those reported from other workers which indicate the fatigue properties of the new alloys to match, and often exceed those of 'conventional' aluminium alloys. Notwithstanding this, a point of concern has arisen in testing of 8090 sheet which, although appearing superior to unclad 2014A-T6 sheet at peak stress levels of $>250 \mathrm{MPa}$, has indicated inferior behaviour at lower stress levels, fig. 14. Further testing of 8090 sheet of production grade is currently in progress. However, bushed lugs in 8090-T651 plate have out-performed similar specimens in 7075-T73 while 9052XL samples exhibit very satisfactory properties.

\section{Manufacturing aspects}

During the past few years, it has been demonstrated that aluminium-lithium alloys are amenable to manufacture in all wrought product forms and at WESTLAND HELICOPTERS, cold forming of 8090 sheet has been accomplished even more readily than with corresponding 2014A alloys, while the machining characteristics of $8090,8091,2091$ and $9052 \mathrm{XL}$ have been found to be indistinguishable from 'conventional' aluminium alloys. Aluminium-lithium extrudability is reported to be excellent with the implication that sections of greater complexity may be produced by this method, although a negative aspect is the occasional increased difficulty of post-extrusion straightening arising from the inherently higher modulus. Forgeability is similarly good although there is a need to introduce post-solution treatment cold work in some of the ingot metallurgy alloys if adequate precipitation strengthening is to be achieved. Tube and wire have been successfully produced. To date, two methods of metal joining have been investigated at WESTLAND HELICOPTERS. Spot welding has presented no difficulties with many joints being superior to those achieved in 'conventional' aluminium alloys. However, more work is required to develop suitable adhesive bonding methods as bond strengths to date using standard chromic acid anodising techniques as a pre-treatment have been inferior to bonds achieved with 2014A alloy sheet, the new alloys appearing to show greater sensitivity to the anodising conditions since failure appears to be associated with the premature detachment of the primer from the anodic film prior to cohesive failure of the adhesive. However, painting using conventional pickling and anodising treatments together with alochrom repair techniques. have presented no problems. 


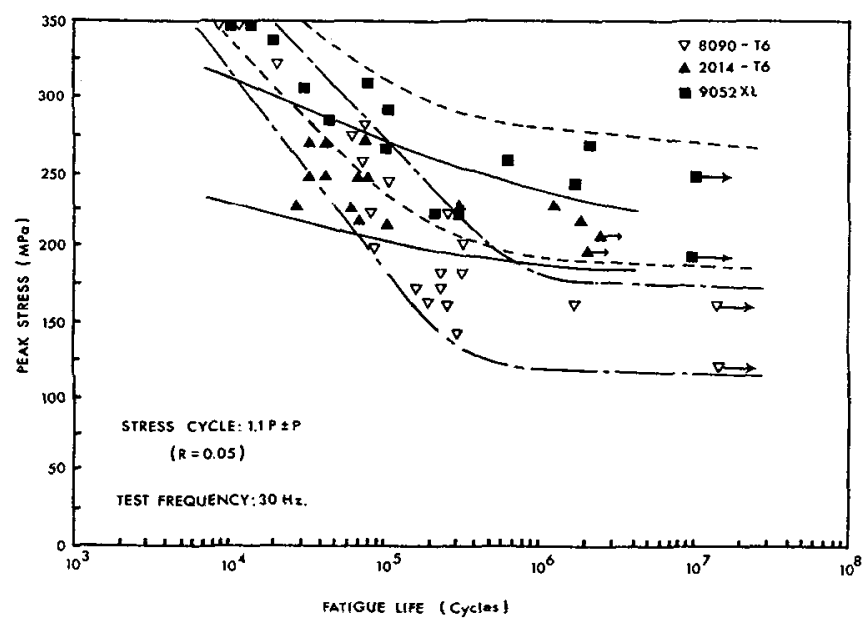

Fig. 14. Comparison of axial fatigue behaviour of longitudinal samples of $0.7-2.0 \mathrm{~mm} 8090,2014 \mathrm{~A}$ and $9052 \times L$ alloys.

\section{Conclusions}

In summary, it appears that the major deficiencies which led to the withdrawal of the previous aluminium-1ithium based alloy 2020 have been overcome and while recognising that the new alloys exhibit some differing characteristics compared to their currently used counterparts, their increasing use to effect significant weight reductions in both fixed and rotary winged aircraft structure is optimistically anticipated.

\section{Acknowledgements}

The author is indebted to UESTLAND HELICOPTERS LTD for permission to publish this paper and in particular to Messrs B C Gittos and N L Bottrell, without whose effort and help this paper could not have been written. Appreciation is also expressed to the Procurement Executive, Ministry of Defence, for partial financial support of the work and to Drs. D S McDarmaid and $C J$ Peel of RAE Farnborough for many useful technical discussions.

\section{References}

1. E.S.Balmuth and R.Schmidt. Proceedings of the First International Aluminium-Lithium Conference, Stone Mountain, Ga. May 1980, Met.Soc. A.I.M.E., 1981, 69-88.

2. B.Noble and G.E.Thompson. Met.Sci.J., 1971., 5, 114.

3. B.Noble, S.J.Harris and K.Dinsdale, Metal Science, 16, 1982, 425.

4. P.J.Gregson and H.M.Flower, Acta Met., (1985), 33, 527.

5. R.F.Ashton, D.S.Thompson, E.A.Starke and F.S.Lin, Proceedings of the Third International Aluminium Lithium Conference, Oxford, England. July 1985. Institute of Metals, 1986, 66.

6. P.A.Lovett, The Metallurgist and Materials Technologist (1983), 15 (9), 443

7. J.S.Benjamin and M.J.Bomford, Met.Trans.A. (August 1977), 8A, 1301. 
8. P.S.Gilman and S.J.Donachie. Proceedings of the Second International Aluminium-Li thium Conference, Monterey, Ca. April 1983. Met.Soc. A.I.M.E., $1984,507$.

9. P.S.Gilman, J.W.Brooks and P.J.Bridges, Ibid ref. 5., 112.

10. C.J.Peel, B.Evans, C.A.Baker, D.A.Bennet t, P.J.Gregson and H.M.FIower Ibid ref. 8,363 .

11. J.M.Papazian, R.L.Schutte and P.N.Adler, Proceedings of International Conference on Ion Beam Analysis, 7=12 July, 1985.

12. A.F.Smith. Paper 114. This Conference. 